\title{
APROVEITAMENTO DE RESÍDUOS DO SANEAMENTO BÁSICO NA FABRICAÇÃO DE CERÂMICA VERMELHA
}

\author{
Ana Carolina Chaves Catolico ${ }^{1}$
}

Luciana Crivelare Gomes Carvalho

Natalia Alegreiro Jarque ${ }^{3}$

\begin{abstract}
RESUMO
Atualmente o lodo é dentre as diversas tipologias de resíduos produzidos nas estações de esgoto sanitário, o que apresenta maior problema quanto a disposição final. Isto se deve ao fato do gerenciamento deste material representar até $60 \%$ do custo operacional. No Brasil, apenas $40,2 \%$ da população urbana possui sistema de coleta de esgoto, deste volume somente $40 \%$ recebe tratamento adequado, gerando uma produção de lodo estimada em 200 mil toneladas. A partir deste expressivo volume produzido, é indiscutível a necessidade e importância da reciclagem e reuso deste material. Partindo desse pressuposto, caminhou-se em direção a discussão da possibilidade de reutilização dos lodos sanitários como matériaprima na indústria de cerâmica, ressaltando tanto os benefícios ambientais quanto econômicos. Sendo assim, o artigo tem como objetivo avaliar a viabilidade da utilização do lodo produzido pela ETE de Barueiri na produção de cerâmica vermelha, baseado em técnicas de aproveitamento de resíduos já utilizadas nos estados do Paraná e Rio Grande do Norte. Devido a facilidade de aceitação deste tipo de produto na construção civil, espera-se ampliar o uso da técnica analisada nas estações que apresentam as condições adequadas, além de incentivar a implementação de novos materiais reciclados no ciclo produtivo de outros setores industriais.
\end{abstract}

PALAVRAS-CHAVE: Saneamento. Cerâmica Vermelha. Lodo.

\section{WASTE UTILIZATION OF SANITATION IN MANUFACTURING OF RED CERAMIC}

\begin{abstract}
Currently, among the various typologies of the waste produced in the sanitary sewer stations, the sludge is the one with the greatest problem concerning the final disposal. This fact is due to the managing of this material that represents by $60 \%$ of the running cost. In Brazil, only $40,2 \%$ of the urban population has sewage collection system. Only $40 \%$ of this volume receives the appropriate treatment, which produces approximately 200.000 tons of sludge. From this expressive volume that is produced, the need and the relevance of recycling and reusing this

\footnotetext{
${ }^{1}$ Mestranda em Engenharia Urbana/ Universidade Federal do Rio de Janeiro/ anacatolico@gmail.com

${ }^{2}$ Mestranda em Engenharia Urbana/ Universidade Federal do Rio de Janeiro/.luciana.crivelare@poli.ufrj.br

${ }^{3}$ Mestranda em Engenharia Urbana/ Universidade Federal do Rio de Janeiro/ arq.nataliajarque@yahoo.com.br
} 


\section{Periódica Eletrânica \\ Fórum Ambiental}

da Alta Paulista

material is unquestionable. This assumption led to discussing the possibility of reusing the sanitary sludge as raw material in the ceramic industry, which would generate not only environmental benefits but also economic ones. Thus, this article intends to evaluate the viability of using the sludge from the ETE Barueri to produce red ceramics, based on the techniques of waste reuse that are already being applied in Paraná and Rio Grande do Norte. Due to the good acceptance of this type of product in the construction industry, it is hoped that the use of the technique here analysed can be expanded in the stations that have the adequate conditions. It is also hoped to encourage the implementation of new recycled material in the productive cycle of other industrial sectors.

KEYWORDS: Sanitation. Red Ceramics. Sludge

\section{RESIDUOS UTILIZACIÓN DE SANEAMIENTO EN LA FABRICACIÓN DE CERÁMICA ROJO}

\section{RESUMEN}

Actualmente el lodo se encuentra entre los distintos tipos de residuos producidos en las estaciones de aguas residuales, que presenta mayor problema, ya que la disposición. Esto es debido a la gestión de este material representa hasta el $60 \%$ de los costos operativos. En Brasil, sólo el 40,2\% de la población urbana tiene sistema de recolección de aguas servidas, este volumen sólo el $40 \%$ recibe tratamiento adecuado, generando una producción de lodos estimado en 200 mil toneladas. A partir de este importante volumen producido, es indiscutible la necesidad y la importancia del reciclaje y la reutilización de este material. Sobre la base de esta hipótesis, se dirigió hacia la discusión de la posibilidad de reutilización de los lodos sanitarios como materia prima en la industria cerámica, destacando tanto los beneficios ambientales y económicos.

Así, el artículo tiene por objeto evaluar la viabilidad de la utilización de los lodos producidos por Barueiri de ETE en la producción de cerámica de color rojo, con base en técnicas de recuperación de residuos que ya se utilizan en los estados de Paraná y Rio Grande do Norte. Debido a la facilidad de aceptación de este tipo de productos en la construcción, se espera ampliar el uso de la técnica analizada en estaciones que cuentan con las condiciones adecuadas, y fomentar la aplicación de nuevos materiales reciclados en el ciclo de producción de otros sectores industriales.

PALABRAS CLAVE: Saneamiento. Cerámicas rojas. Lodos.

\section{Introdução}

Nas estações de esgoto sanitário (ETE), o lodo é um dos tipos de resíduos produzidos que apresenta maiores problemas quanto a sua disposição final. Isto se deve ao fato de que o gerenciamento deste material pode representar de $20 \%$ a $60 \%$ do custo operacional total. Essa variação é significativa e é dependente de alguns fatores, como por exemplo, a distância entre a estação de tratamento e o local destinado ao processamento e armazenamento do resíduo ou, ainda, a tipologia do lodo.

No Brasil, ao longo dos anos, o planejamento e a execução do destino final dos resíduos provenientes do tratamento do esgoto têm sido feita, na 
maioria das vezes, de forma negligente. Como consequência deste descaso aparente pode se constatar, através dos dados emitidos pelo IBGE (2004), que apenas $40,12 \%$ da população urbana possui sistema de coleta de esgoto. Do volume coletado atualmente, apenas $40 \%$ recebe tratamento adequado, gerando perspectivas significativas de crescimento e de geração de lodo.

Baseado no percentual sinalizado pelo IBGE, a produção de lodo no Brasil pode ser estimada entre 150 e 220 mil em toneladas de matéria desidratada por ano. Este dado pode ser ainda maior se todo o esgoto hoje coletado fosse também tratado de forma eficiente, assim o volume de lodo produzido chegaria a 473 mil toneladas por ano. A partir deste expressivo volume produzido, é indiscutível a necessidade e importância da reciclagem e do reuso deste material. Grande parte dele, até recentemente, era lançado indiscriminadamente em sistemas pluviais (rios, lagos e lagoas). Porém, com a evolução da legislação ambiental, as operadoras vêm sendo obrigadas a destinar adequadamente estes resíduos.

O avanço da tecnologia somado a demanda proveniente do crescimento populacional, ocasionou um grande desequilíbrio entre o consumo e a reutilização, e teve como consequência a crescente poluição do meio ambiente, fruto de uma gestão inadequada dos resíduos. Pensando nisso, avalia-se a necessidade em atingir um novo equilíbrio, entre esse crescimento das demandas por matérias e a geração de resíduos. Atualmente, novas técnicas e metodologias para reestabelecer este equilíbrio vem sendo desenvolvidas, um exemplo disto pode ser visto na construção civil, que vem trabalhando de maneira crescente no reaproveitamento ou utilização dos resíduos sólidos provenientes de sua própria construção.

A utilização de lodos de estações de tratamento de esgotos como matéria-prima na indústria cerâmica é uma prática que vem sendo adotada em vários países industrializados (Alemanha, Espanha, EEUU e Japão, dentre outros). No Brasil existem diversas pesquisas sobre o assunto, no entanto, a reciclagem de resíduos ainda não exerce um papel significativo neste nicho de mercado. Entre as razões, destaca-se a falta de integração da pesquisa 


\section{Periódica Eletrânica

brasileira com a internacional, a falta de incentivo às indústrias e a falta de tecnologia adequada.

A indústria cerâmica tem sido alvo de diversas pesquisas com incorporação de resíduos, devido a facilidade de aceitação na construção civil, este fato é um grande incentivo a implementação de novos materiais como componentes em matéria prima. Esses materiais são avaliados para fabricação de telhas, tijolos, cimento, etc.

A reciclagem na construção civil vem se consolidando como uma prática sustentável, atenuando os riscos de impactos ambientais e reduzindo os custos de produção no setor. Além disso, se apresenta como oportunidade de transformar um item de despesa em fonte de faturamento, ou pelo menos, minimizando as despesas da disposição final desse residuo. Torna-se também um fator de incentivo ao aproveitamento de resíduos que antes não tinham destino final adequado. Dentre os beneficios podemos destacar: redução no consumo de recursos naturais não renováveis; redução de área necessária para aterro (devido a minimização do volume dos resíduos) e redução e controle da poluição.

Existem algumas vantagens na utilização do lodo da ETE para a fabricação da cerâmica vermelha em relação a outros tipos de uso, pois as operações inerentes à indústria cerâmica (fornos com altas temperaturas) fazem com que os riscos sanitários se reduzam ao mínimo. Como principais vantagens, do uso de lodo com esta finalidade, podemos destacar: a destinação ambientalmente segura para resíduos potencialmente perigosos (lodos); o menor gasto de energia, transporte e fabricação, e a menor utilização dos recursos naturais.

Visto a importância da reutilização e do reaproveitamento dos resíduos produzidos na ETE, este trabalho tem como objetivo avaliar a viabilidade da utilização do lodo produzido pela Estação de Tratamento de Barueiri (SP) na produção de cerâmica vermelha, baseado neste tipo de aproveitamento que já vem sendo realizado nos estados do Paraná e Rio Grande do Norte.

Além disso, busca-se também levantar reflexões, não só na academia, mas também em todos aqueles que se veêm interessados na temática 
ambiental, a compreenderem um pouco mais sobre a possibilidade, assim como a importância da reutilização do lodo. Para exemplificar e facilitar a compreensão dos participantes, foi usado o caso da fabricação da cerâmica vermelha, assunto ainda pouco discutido neste meio.

\section{Revisão bibliográfica}

O tratamento de esgoto sanitário se caracteriza pela remoção de contaminantes das águas residuais através de processos físicos, químicos ou biológicos, tendo como resultado um efluente líquido e resíduos sólidos. $O$ processo é constituído de inúmeros estágios que incluem fases preliminares, primárias, secundárias e terciárias, como pode-se visualizar na figura 1.

A fase preliminar consiste na remoção de sólidos grosseiros, como gravetos, panos, areia, cascalho e grandes partículas de alimentos, garantindo assim a integralidade da estação e evitando a degradação da estrutura da mesma. São utilizados equipamentos como grades e peneiras. No processo primário tem-se o início da remoção dos contaminantes através da decantação e remoção de sólidos.

Figura 1: Esquema exemplificando as fases de uma ETE que utiliza lodos ativados.

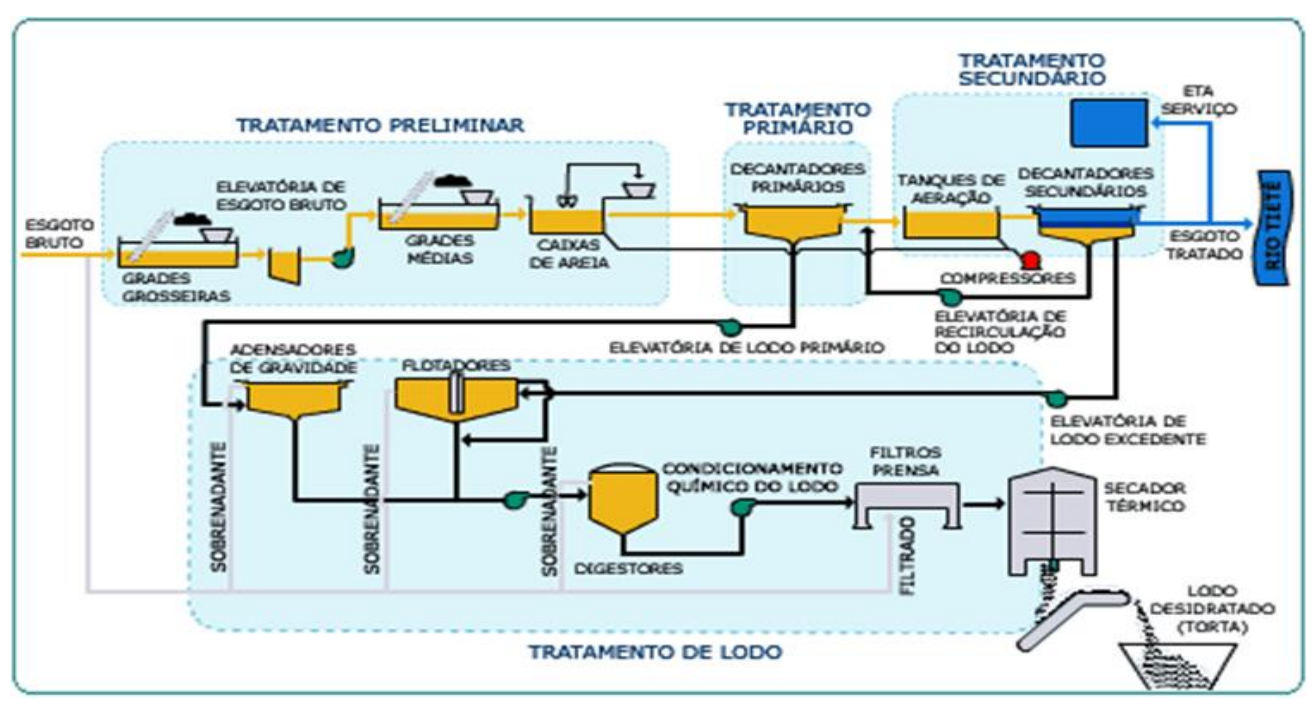

Fonte: SABESP. 


\section{Periódica Eletrânica \\ Fórum Ambiental}

da Alta Paulista
Volume 11, Número 09, 2015

Produção e as

Tecnologias Sustentáveis

A fase secundária tem como objetivo a remoção da matéria orgânica a fim de que se possa atingir os limites permitidos de lançamento. O tipo de tratamento mais utilizado no Brasil é o de lodo ativado, onde o esgoto afluente passa por um processo biológico na presença de oxigênio dissolvido, agitação mecânica e microorganismos específicos. O processo é constituído de duas unidades: tanque de aeração e decantador secundário. Na primeira unidade ocorre a decomposição aeróbica do substrato orgânico solúvel e a formação de flocos biológicos para posterior sedimentação no decantador secundário. Os sólidos sedimentados são recirculados, mantendo assim, a elevada concentração de biomassa no tanque de aeração. O retorno do lodo mantêm uma relação alimento/microorganismo capaz de decompor com maior eficiência o material orgânico. Uma parcela dos sólidos sedimentados e não circulado é removida do processo, o que denominamos de lodo secundário (produção excedente de lodo). O efluente líquido oriundo do decantador secundário é descartado diretamente para o corpo receptor ou pode passar por um tratamento caso venha a ser reutilizado internamente ou para usos menos nobres como lavagem de ruas e rega de jardins.

Os processos de estabilização do lodo têm por objetivo atenuar o odor e a quantidade de microorganismos patogênicos, de acordo com o destino final previsto para o resíduo. Portanto, esta fase deve ser definida e articulada em conjunto com a concepção do sistema, de modo a evitar trasntornos e impactos devido à falta de planejamento e de estratégia para a utilização e/ou disposição desses resíduos. A estabilização pode ser realizada através de processos químicos, físicos e biológicos (digestão anaeróbia, aeróbia, aeróbia autotérmica e compostagem). A secagem térmica também pode ser classificada como uma forma de estabilização.

A quantidade de lodo de esgoto vem crescendo proporcionalmente ao aumento da oferta de serviços de coleta e tratamento, que por sua vez, deve acompanhar o crescimento populacional. No Brasil podemos observar um déficit deste serviço, já que o tratamento de esgoto atinge apenas cerca de $40 \%$ da população urbana. Além disso, apesar da grande quantidade de lodo gerada, as práticas de reuso deste lodo são pouco utilizadas. Infelizmente, o 


\section{Periódica Eletrônica

destino desses resíduos das estações de tratamento tem sido os sistemas hídricos mais próximos.

Um exemplo de aproveitamento de lodo no Brasil é o realizado nos estados do Paraná (SANEPAR) e Rio Grande do Norte, onde o lodo está sendo implementado na fabricação de cerâmicas vermelhas. Sendo assim, este trabalho teve como base duas pesquisas realizadas na tentativa de confirmar a viabilidade do uso de lodo do ETA e do ETE na produção de cerâmica, uma vez que, dependendo de como e quanto for adicionado do mesmo, o material produzido - blocos de cerâmica vermelha - poderá perder a sua qualidade. 0 que, de fato, não interessaria para as indústrias. Na crença de que está forma de produção possa vir a ser utilizada de modo habitual ou costumeiro, é de grande importância a real qualidade do material aqui apresentado.

A incorporação de argilas sempre foi comum na fabricação de cerâmica. O diferencial deste estudo aqui explanado é a inserção - ainda no estado pastoso - facilitando o processo de mistura da massa, tornando mais ágil o processo e, conseqüentemente, mais barata a produção. Quanto mais homogênea a massa for (resultado da produção de uma massa mais pastosa), melhor também será a qualidade dos blocos de cerâmica produzios.

Como foi citado no parágrafo acima, serão tratados aqui neste trabalho dois experimentos que foram realizados no Paraná - SANEPAR - e outro no Rio Grande do Norte que visaram maximizar a adição do lodo na massa cerâmica. Primeiramente, o lodo foi adicionado com a umidade comum que é produzida na rotina operacional do tratamento de esgoto. Logo depois, a tentativa foi diminuir cada vez mais a umidade do mesmo.

\section{Cerâmica Vermelha: processo de produção}

Antes da análise acerca da incorporação do lodo, torna-se importante tomar conhecimento do processo de produção das cerâmicas. Para a fabricação são necessárias várias etapas, que podem incluir desde a exploração na jazida, tratamento prévio da matéria-prima, passando pela homogeneização, moldagem e secagem do material, até a sua queima. É nesta 
última etapa que ocorrem as reações que farão com que os produtos adquiram as propriedades desejadas em função do uso ou emprego a que se destinam.

Figura 2: Fluxograma do processo produtivo da cerâmica vermelha

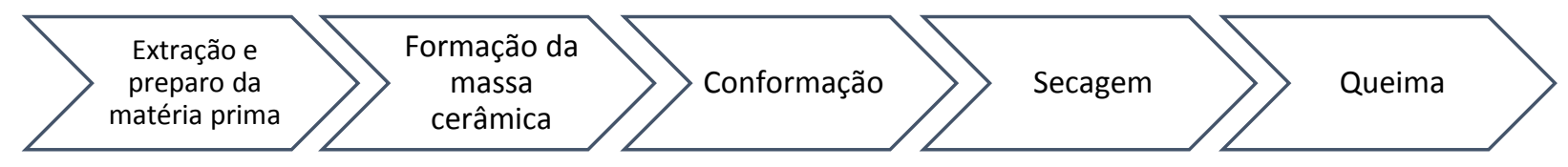

Fonte: Elaboração própria.

1) Extração e preparo da matéria prima

Grande parte da matéria-prima utilizada na indústria cerâmica tradicional e de revestimento é natural e encontra-se em depósitos espalhados por todo território nacional em diversos países. Após a extração do material e estocagem, ele é tratado através de processos de depuração ou purificação, divisão, homogeneização e obtenção da umidade adequada da matéria-prima, essas operações precedem a fabricação propriamente dita dos produtos cerâmicos, que é compreendida pela moldagem, secagem e a queima ou cozimento dos mesmos (FALÇÃO,1988).

A depuração acontece com 0 objetivo de eliminar determinadas impurezas como grãos duros e matéria orgânica, entre outros elementos que possam dificultar o seu processo de tratamento mecânico e posteriormente dão origem a uma secagem anormal, têm ação química prejudicial o que acarreta na diminuição da qualidade do produto fabricado.

2) Formação da massa cerâmica: inserção do lodo

Os materiais cerâmicos podem ser fabricados de diversas formas a partir da composição de duas ou mais matérias-primas, aditivos e água ou outro meio. Essa composição deve ser estabelecida de acordo com as características e composições das diferentes matérias-primas. A partir disso defini-se então o processo de conformação e a faixa de queima desejada, respeitando sempre a classe de cada produto.

Para a fabricação da cerâmica vermelha se utiliza apenas argila como matéria-prima, normalmente dois ou mais tipos de argila com características 
diferentes entram na sua composição. A dosagem das matérias-primas e dos aditivos é considerada uma das etapas fundamentais do processo de fabricação desses produtos cerâmicos. Os diferentes tipos de massa resultantes desse processo podem ser preparados de acordo com o produto almejado e a técnica a ser empregada para dar forma às peças (PIRES,2006).

$\mathrm{Na}$ cerâmica vermelha $\mathrm{o}$ interesse recai na preparação de massas plásticas, principalmente para extrusão. A formulação das massas é feita a base de composições químicas das matérias-primas, onde para formular uma determinada massa uma série de ensaios químicos e físicos são realizados, a fim de testar a eficiência do material. Para garantir as propriedades finais do corpo cerâmico é fundamental o tratamento adequado da matéria-prima e a correção das suas propriedades físico-químicas. Isto se faz necessário para viabilizar sua conformação e seu manuseio. Uma das vantagens da incorporação do lodo na formação da massa é a possibilidade de correção de umidade.

O grau de umidade, a granulometria e a presença de matéria orgânica são as propriedades que conferem a plasticidade apropriada para a modelagem dos produtos. A natureza das argilas disponíveis é o fator que determina qual o tipo de equipamento e tecnologia mais adequados para uma determinada fábrica. As argilas secundárias, como as de várzea, geralmente são submetidas à modalidade de preparação conhecida como preparação por via semi-úmida. Porém, quando as argilas disponíveis são muito duras, os equipamentos convencionais da preparação por via semi-úmida não conseguem desagregá-las e destruir completamente os torrões, o que pode dificultar as etapas de processamento posteriores e comprometer as propriedades do produto final.

Através das características do lodo proveniente do tratamento sanitário pode-se observar a possível incorporação destes resíduos na massa cerâmica, pois eles apresentam componentes interessantes (argilo-minerais) e prejudiciais (material orgânico e umidade elevada) à massa cerâmica em quantidades excessivas. Sendo assim é importante ressaltar, contudo que a 
adição destes resíduos demandará um ajuste tanto na formação da massa cerâmica quanto no processo de produção (MAGALHÃES,2003).

Para que seja possível adequar as características da massa de cerâmica produzida de acordo com as especificações definidas pelo seu uso, é realizado um controle de dosagem, onde a quantidade de resíduos incorporada à matéria-prima possui uma variação de percentual, que varia de acordo com a função do tipo de resíduo e do processo no qual ele será utilizado. Esse controle é necessário, a fim de que seja evitado que as propriedades mecânicas, retração e absorção sejam modificadas.

O lodo utilizado para fabricação passa por um processo de desidratação, apresentando aspecto granular e teor de sólidos da ordem de $45 \%$. Nas condições normais de fabricação, o lodo de água apresenta $12 \%$ de sólidos enquanto o de ETE apresenta $45 \%$. Isso significa que o lodo de água foi considerado não-plástico, e o lodo de esgoto foi considerado lodo plástico. Um com elasticidade e o outro não, ou seja, um tende a fabricar cerâmicas mais confiáveis e o outro não. Percebeu-se que quanto maior era a dosagem do lodo de água, a consistência era mais mole, por outro lado, se fosse o lodo de esgoto, muito seco, os blocos se tornavam quebradiços.

Foram feitas 5 tentativas de medição de lodo de ETE e de ETA para saber qual seria a melhor escolha para a fabricação. A do lodo de ETE varia de $2,2 \%$ e $36 \%$ e a de lodo de ETA varia de $1,7 \%$ a $8,3 \%$, concluindo que 0 melhor seria $4,2 \%$ de lodo de ETA. As maiores dosagens do lodo de ETA desestabilizaram a massa cerâmica. Inferindo que dois pontos são fatores limitantes nesse processo: a umidade e a perda ao fogo. O primeiro dificultando o processo operacional e o segundo comprometendo a qualidade do bloco feito a partir da cerâmica vermelha e lodo.

As etapas e conclusões mencionadas servem para o Paraná e para o Rio Grande do Norte. A grande diferença entre os dois encontra-se nisso: no Paraná a secagem da cerâmica ocorreu em um pátio aberto num tempo de 30 dias. No Rio Grande do Norte, foram queimados em laboratórios, de $850^{\circ} \mathrm{C}$ a $1050{ }^{\circ} \mathrm{C}$. Utilizou-se somente o lodo de esgoto, mas de origens diferentes, sendo eleitos o melhor lodo através, conseqüentemente, da melhor qualidade 


\section{Periódica Eletrônica

do bloco de cerâmica. Inferiu-se também que a taxa de umidade boa para a produção de cerâmica está entre 10 e 30\%.

3) Conformação

É a etapa de fabricação responsável pela característiica geométrica do produto. Existem vários métodos de conformação, são eles: colagem de louças, extrusão de blocos, telhas, prensagem de telhas, etc. A escolha do método tem relação direta com as condições de trabalho da massa, da dimensão da peça, das dificuldades de fabricação, das tolerâncias, do fator econômico, entre outros. O método de conformação mais usado é o de extrusão, que é utilizado em cerâmicas confeccionadas com massas plásticas. Por esse métodos são conformadas peças de seção transversal regular, tais como: blocos, telhas, tijolos vazados, lajes e lajotas.

4) Secagem

Essa etapa acontece posteriormente à etapa de conformação e tem como objetivo principal eliminar toda a água proveniente da preparação da massa através da evaporação que acontece de forma lenta e gradual, a fim de evitar tensões. As peças cerâmicas são consideradas tecnicamente secas, quando sua umidade residual atinge cerca de 1 a $2 \%$. A secagem da massa pode ser influenciada por diversos fatores, entre eles a temperatura, a umidade relativa do ar, a velocidade e a direção de aplicação do ar, etc.

\section{5) Queima}

Considerada a etapa mais importante de todo o processo de fabricação dos materiais cerâmicos, pois durante a queima ocorre a sinterização que determina as propriedades finais do produto. $O$ processo de queima é diretamente influenciado não apenas pela temperatura alcançada, mas também pela velocidade de aquecimento, de resfriamento, atmosférica ambiente, tipo de forno e combustível utilizado. Por isso é nessa etapa que aparece grande número de defeitos provenientes das etapas anteriores da produção, incluindo presença de impurezas na matéria-prima, preparação de massas, conformação das peças, secagem e arranjo de queima. A qualidade do produto está totalmente vinculada ao tempo de queima da peça, pois a queima rápida economicamente é interessante, porém o resultado final não será o esperado. 


\subsection{Questão Econômica da Inserção do Lodo na Produção de Cerâmica}

O lodo quase sempre é enxergado como um problema dispendioso e problemático na ETE e na ETA. Todas as destinações que podem ser dadas a ele não são tão sustentáveis quanto a sua possibilidade de reutilização como, por exemplo, na agricultura ou mesmo na produção de cerâmica, como se defende neste dado trabalho.

Porém seja na agricultura, seja na incineração, ou até mesmo na deposição oceânica, todos tem um grande gasto, como pode-se perceber nas tabelas 1 e 2, onde o custo utilizando-se a argila como matéria-prima representa 7\% do custo total na ETE do Rio Grande do Norte e 21\% na ETE do Paraná. Sendo assim, este estudo buscou provar que a indústria de cerâmica se beneficiaria com a utilização de lodo como matéria-prima.

Tabela 1: Estimativa de custo na ETE do Rio Grande do Norte.

\begin{tabular}{|c|c|c|c|}
\hline $\begin{array}{c}\text { Matéria-prima, funcionário e } \\
\text { encargos trabalhistas }\end{array}$ & $\begin{array}{c}\text { Consumo } \\
\text { Mensal }\end{array}$ & $\begin{array}{c}\text { Custo Mensal } \\
(\mathrm{R} \$)\end{array}$ & $\begin{array}{c}\text { Valor Percentual } \\
(\%)\end{array}$ \\
\hline Argila & $420 \mathrm{~m}^{3}$ & $1.610,00$ & 7,50 \\
\hline Lenha & $571,42 \mathrm{~m}$ & $7.619,05$ & 35,00 \\
\hline Energia e água* & - & $2.500,00$ & 11,50 \\
\hline trabalhistas & - & $10.000,00$ & 46,00 \\
\hline \multicolumn{2}{|c|}{ Total } & $21.729,05$ & 100 \\
\hline
\end{tabular}

*Considerou-se o valor de R\$2.500,00 gastos com energia e água. Fonte: UFRN, 2007.

Tabela 2: Estimativa de custo para a ETE do Paraná.

\begin{tabular}{|c|c|c|}
\hline & Custo Mensal (R\$) & Valor Percentual (\%) \\
\hline Argila + Transporte & $4.400,00$ & 20,95 \\
\hline Lenha & $10.875,00$ & 51,77 \\
\hline Energia & $2.000,00$ & 9,52 \\
\hline Água & $1.000,00$ & 4,76 \\
\hline Funcionários & $2.730,00$ & 13,00 \\
\hline Total & $21.005,00$ & 100 \\
\hline
\end{tabular}

Fonte: SANEPAR, 2007 
Como a pesquisa que abordou este tema tem um caráter muito técnico, e esse não é o objetivo central do trabalho agora apresentando, de forma sintetizada, será exposto que foi realizado um longo levantamento econômico de todas as possibilidades sejam elas referente à disposição do lodo, sejam elas referentes a outras possibilidades de matéria prima para a produção de blocos de cerâmica vermelha. Chegou-se a conclusão de que os dados expostos anteriormente foram os mais viáveis e lucrativos, e, logicamente, sustentáveis.

\subsection{Estudo de caso: ETE Barueri (SP)}

A metodologia deste trabalho orientou-se pela pesquisa qualitativa, fazendo uso tanto da pesquisa bibliográfica quanto da pesquisa exploratória com base em estudos realizados sobre o tema. Foram utilizados como base técnica e metodológica para o presente estudo de caso da ETE de Barueri, os experimentos realizados pela SANEPAR no estado do Paraná e Rio Grande do Norte. O acompanhamento da Estação de Tratamento de Esgoto da Universidade Federal do Rio de Janeiro contribui para uma compreensão mais profunda de todo o processo de tratamento de estgoto, assim como a possibilidade de reutilização do lodo para a fabricação de cerâmica. $\mathrm{Na}$ Estação de Tratamento de esgoto Barueri (SP) foram realizadas análises quantitativas e tipológicas do lodo gerado a fim de se estudar a viabilidade da utilização deste lodo na fabricação de cerâmicas vermelhas.

A ETE de Barueri pertence a SABESP (Companhia de Saneamento Básico do Estado de São Paulo) e é a maior estação da região metropolitana paulista e da América Latina, tendo capacidade para tratar 9,5 mil litros de esgoto por segundo e beneficiar 4,5 milhões de pessoas. Ela serve a maior parte da cidade de São Paulo e aos municípios de Jandira, Itapevi, Barueri, Carapicuíba, Osasco, Taboão da Serra e partes da Cotia e Embu. Atualmente apresenta uma produção de lodo de $7.780 \mathrm{l} / \mathrm{s}$ ou 230 ton/d.

Um dos fatores que levaram a escolha desta estação foi a obra de ampliação que está prevista, o que facilitaria a implantação dos equipamentos 
que viriam a ser necessários para promover o tratamento e posterior aproveitamento do lodo de esgoto. Sua capacidade será ampliada de 9,5 $\mathrm{m}^{3} / \mathrm{s}$ para $11 \mathrm{~m}^{3} / \mathrm{s}$, além da construção de dois tanques de decantação primária e outros dois de decantação secundária (diâmetro de $46 \mathrm{~m}$, profundidade útil de $4 \mathrm{~m}$, área unitária de $1.661 \mathrm{~m}^{2}$ e volume unitário de $6.644 \mathrm{~m}^{3}$ ), na fase líquida do tratamento. Os novos decantadores secundários exigirão a instalação de uma elevatória de retorno de lodo adicional, constituída de bombas centrífugas, com sucção simples. Esse lodo será conduzido aos tanques de aeração já exitentes e o efluente será lançado no rio Tietê ( $92 \%$ limpo).

O processo de tratamento utilizado é o de lodos ativados convencional. O lodo preveniente passa por um filtro prensa de placas que força a água do lodo sob alta pressão e em seguida é desidratado, onde se reduz o volume do lodo em excesso por meio da redução de seu teor de umidade (figura 3).

Figura 3: Esquema do processo de tratamento da ETE Barueri.

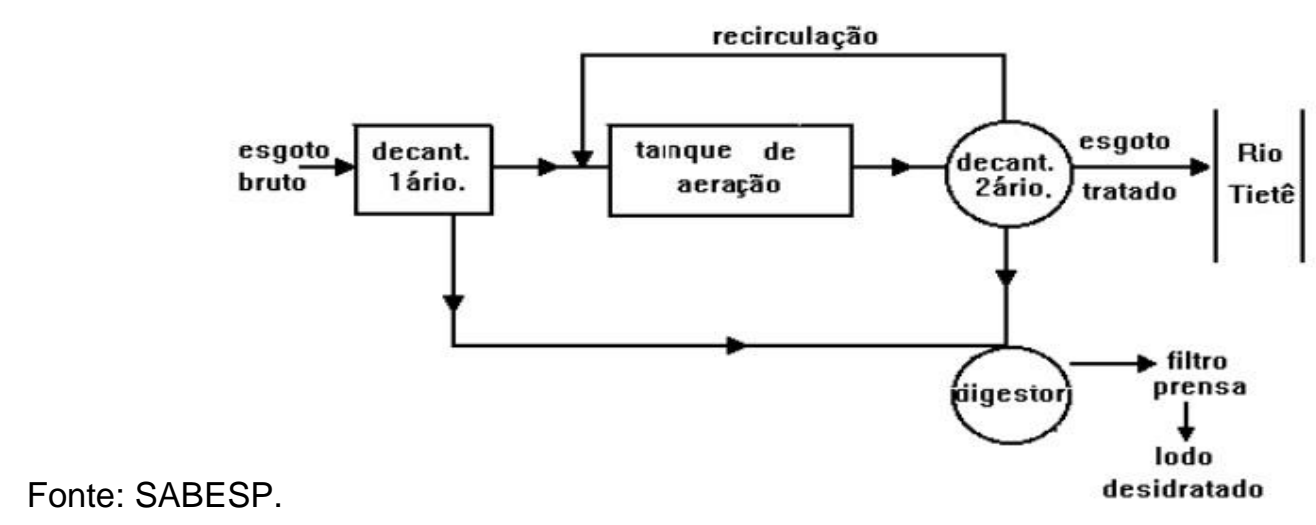

Desde o início da operação da ETE em 1988, fatores de ordem técnica e econômica levaram a disposição dos resíduos a céu aberto, em áreas livres do terreno da própria estação, que foi adotada em caráter provisório e precário até que se dispusesse de local ambientalmente adequado para recebê-los em caráter definitivo. Por causa disto, praticamente todo o lodo produzido pela ETE desde 1988 permaneceu acumulado no terreno da estação, resultando em 1994 em um volume aproximado de $215.000 \mathrm{~m}^{3}$ de resíduos dispostos ao ar livre, em pilhas e camadas colocadas diretamente sobre o solo. 
O lodo condicionado desidratado foi sendo depositado no terreno à medida em que era gerado. Ele apresenta valores médios de umidade e pH de $63 \%$ e $11 \%$ respectivamente. Em relação a concentração de metais pesados ele pode ser considerado de boa qualidade (Tabela 3). A umidade, e consequentemente o nível de plasticidade adquirido, são considerados fatores decisivos para a utilização do lodo na produção de cerâmica vermelha, sendo necessário que a umidade esteja numa faixa de 10\%-30\%. Portanto, pode-se concluir que o lodo produzido pela estação encontra-se dentro dos limites desejados.

Tabela 3: Comparação entre os valores de metais pesados encontrados na ETE Barueri e limites permitidos pela EPA (Environmental Protection Agency).

\begin{tabular}{ccccc}
\hline $\begin{array}{c}\text { Metal } \\
\text { Pesado }\end{array}$ & $\begin{array}{c}\text { Concentração no } \\
\text { lodo da ETE-Barueri }\end{array}$ & $\begin{array}{c}\text { Concentração } \\
\text { máxima no lodo* }\end{array}$ & $\begin{array}{c}\text { Taxa máxima de } \\
\text { aplicação anual* }\end{array}$ & $\begin{array}{c}\text { Taxa máxima de } \\
\text { aplicação } \\
\text { acumulada* }\end{array}$ \\
\hline $\mathbf{~} \mathbf{~ d ~}$ & 12,68 & $\mathbf{m g} / \mathbf{k g}$ & $\mathbf{k g} / \mathbf{h a} . \mathbf{a n o}$ & $\mathbf{k g} / \mathbf{h a}$ \\
$\mathbf{C r}$ & $1.064,93$ & 39,00 & 1,90 & 39,00 \\
$\mathbf{C u}$ & 737,58 & $1.200,00$ & 150,00 & $3.000,00$ \\
$\mathbf{M n}$ & 152,57 & $1.500,00$ & 75,00 & $1.500,00$ \\
$\mathbf{N i}$ & 386,10 & - & - & - \\
$\mathbf{P b}$ & 181,83 & 420,00 & 21,00 & 420,00 \\
$\mathbf{Z n}$ & $1.378,67$ & 300,00 & 15,00 & 300,00 \\
\hline "Limites da EPA (Environmental Protection Agency) & Sieger \& Hermann (1993)
\end{tabular}

Fonte: Sieger \& Hermann, 1993

\section{Conclusão}

A indústria de cerâmica tem sido atualmente alvo de diversas pesquisas acerca da incorporação de resíduos, principalmente devido a sua facilidade de aceitar novos materiais como componentes da matéria prima (lodo de esgoto, resíduos de mineração, escoria de siderúrgicas, pó de cimento, resíduos de galvanoplastia, entre outros). Estes resíduos tem sido avaliados na fabricação de telhas e tijolos, cimento, agregados leves, matriz de cimento Portland, e componentes de mistura asfáltica. Neste sentido, o presente estudo identificou 
o caráter promissor do uso de lodos de esgoto como matéria-prima na industria de cerâmica, visto que, as massas argilosas utilizadas são de natureza heterogénea, aceitando incorporação de materiais residuais de diversos tipos e origens, mesmo quando adicionados em quantidades significantes.

Verificou-se que apesar do conhecimento técnico e benefício ambiental obtidos com o emprego de resíduos na produção da cerâmica vermelha, a sua utilização ainda representa uma porcentagem muito pequena no Brasil. A produção em escala real de tijolos com adição de lodo, apresenta vantagens como o menor consumo de água e de combustível, portanto, esta pode ser classificada como uma forma adequada de disposição do lodo. Além disso, as indústrias se beneficia com a melhoria da sua imagem junto à sociedade e aos órgãos ambientais.

Diante da problemática que o país vive em relação aos desafios do gerenciamento dos altos volumes de resíduos sólidos gerados, a reutilização dos lodos faz com que uma quantidade menor deles esteja disposta em aterros sanitários ou outros locais de disposição, abrindo espaço para outros rejeitos, que por sua vez, não apresentam nenhuma outra opção de destinação final.

Espera-se que este trabalho abra caminho para outros estudos e pesquisas relacionados a temática ambiental como um todo, mas se possível, com ênfase na área de saneamento ambiental e reutilização de lodo, a fim de que esta forma de reaproveitamento passe a ser amplamente aplicada nas áreas em que apresenta viabilidade.

\section{Agradecimentos}

As autoras agradecem a ajuda da professora lene Christie Figueiredo do Programa de Engenharia Urbana da Escola Politécnica, que através de seu perfil investigativo e crítico possibilitou a elaboração e incentivo deste artigo. 


\section{Periádica Eletrânica

\section{Referências Bibliográficas}

AZEVEDO NETTO, J. M. \& BOTELHO, M. H. C. Manual de Saneamento de Cidades e Edificações, PINI Editora, Reimpressão 1995, São Paulo.

FAPESP. Diagnóstico socioambiental, aprendizagem social e modelos multi-agentes na definição de políticas públicas para a gestão integrada dos recursos hídricos e uso e ocupação do solo. 2007. Disponível em: <http://www.usp.br/procam/govagua/embu.php>. Acesso em 19 outubro de 2014.

FERRÃO, Liliâm Maria Ventorim, Et al. Interfaces entre a modernização e qualidade de vida: $O$ caso dos produtores de milho do Estado do Espírito Santo. Oikos, Viçosa, v.16, n.2, p. 63-90, 2005.

ODUM, E.P. Fundamentos da ecologia. (Fundamentals of ecology, 1953). C.M.Baeta Neves (Trad.). 2 ed. Lisboa: Fundação Calouste Gulbenkian, 1976. 595 p.

EIGENHEER, E. M. São Francisco/Nitéroi. In: Emílio Maciel Eigenheer. (Org.). Coleta seletiva de lixo: experiências brasileiras nํㄴ. Niterói, v.4, p.13-18, 2003.

FALCÃO BAUER, L. A. Materiais de construção. Rio de Janeiro: Livros Técnicos, 1988. 529P.

MAGALHÃES, P. F. Estudo da Viabilidade de Incorporação de Lodo de Estação de Água na Produção de Cerâmica Vermelha. Rio de Janeiro, 2003. 110 f. Dissertação (Mestrado em Engenharia Metalúrgica) Pontífica Universidade Católica do Rio de Janeiro.

PIRES, Adriana. Lodo de Esgoto. Revista Ecotur. Disponível em: www.revistaecotour.com.br. Acesso em 20 de outubro de 2014.

LEAL, F. C. T. Sistemas de saneamento ambiental. Faculdade de engenharia da UFJF. Departamento de Hidráulica e Saneamento. Curso de Especialização em análise Ambiental. 4 ed. 2008. Notas de Aula.

PHILIPPI Jr., A. Saneamento, saúde e ambiente: fundamentos para um desenvolvimento sustentável. Coleção Ambiental. Barueri: Ed. Manole, 2004

SABESP, www.sabesp.com.br, acessado em 06 de novembro de 2014 